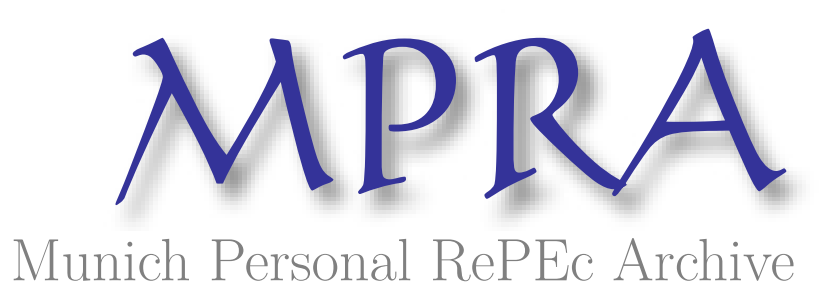

\title{
Two Kinds of Adaptation, Two Kinds of Relativity
}

Kontek, Krzysztof

Artal Investments

19 September 2010

Online at https://mpra.ub.uni-muenchen.de/25169/

MPRA Paper No. 25169, posted 20 Sep 2010 02:32 UTC 


\title{
Two Kinds of Adaptation, Two Kinds of Relativity.
}

\author{
Krzysztof Kontek
}

Artal Investments, Warsaw ${ }^{1}$

\begin{abstract}
This paper presents a review of adaptation concepts at the evolutionary, environmental, neural, sensory, mental and mathematical levels, including Helson's and Parducci's theories of perception and category judgments. Two kinds of adaptation can be clearly distinguished. The first, known as level adaptation, refers to the shift of the neutral perception level to the average stimulus value. It results in a single reference point and stimuli changes represented in absolute terms. This concept is employed by Prospect Theory, which assumes that gains and losses are perceived as monetary amounts. The second kind of adaptation refers to the adjustment of perception sensitivity to stimuli range. It results in two reference points (minimum and maximum stimulus) and stimuli changes perceived in relative terms. Both range adaptation and range relativity are well documented phenomena and have even been confirmed by the creators of Prospect Theory. This makes room for another decision making theory based on the range relativity approach. As shown by Kontek (2009), such a theory would not require the concept of probability weighting to describe lottery experiments or behavioral paradoxes.
\end{abstract}

JEL classification: C91, D03, D81, D87

Keywords: Adaptation-Level Theory, Range-Frequency Theory, Prospect Theory

\section{Introduction}

The term "adaptation" has a broad meaning and is widely used in numerous sciences and has many connotations (especially in biology in an evolutionary context). The term also appears to have psychological associations with the article "Hedonic Adaptation" by Frederick and Loewenstein (1999) being the basic source of information on the subject. The primary motivation for this paper is to clearly distinguish the two kinds of adaptation.

Level adaptation refers to the shifting of the neutral perception level to the average stimulus value. This kind of adaptation was introduced by Helson in "Adaptation-Level The-

\footnotetext{
${ }^{1}$ Contact: ul. Chrościckiego 93/105, 02-414 Warsaw, Poland, e-mail: kkontek2000@yahoo.com.
} 
ory" (1964), and was further implemented by Brickman and Campbell in their "Hedonic Treadmill" hypothesis (1971). Level relativity means that there is a single reference point and that stimuli changes are represented in absolute terms. This concept is employed by Prospect Theory (1979), which assumes that gains and losses are perceived as monetary amounts.

Range adaptation means the adjustment of perception sensitivity to stimuli deviations. This kind of adaptation leads to range relativity, proposed by Parducci in Range-Frequency Theory (1965). Range relativity postulates that there are two reference points (minimum and maximum stimulus value) and stimuli changes are represented in relative terms as a proportion of the stimulus range.

Both range adaptation and range relativity are well documented phenomena and have even been confirmed by the creators of Prospect Theory. For instance Kahneman and Tversky (1984) stated that "people spontaneously frame decisions in terms of topical account" which "leads people to evaluate gains and losses in relative rather than in absolute terms" (emphasis added). This observation, however, was only presented by Kahneman and Tversky a few years after the introduction of Prospect Theory.

This makes room for another decision making theory based on the range relativity approach. It is not, however, the purpose of this paper to present one. It is nevertheless worth mentioning that Kontek (2009) has demonstrated that such a theory would not require the concept of probability weighting to describe lottery experiments or behavioral paradoxes. Even more surprisingly, the resulting utility function would strongly resemble the shape of the utility curve hypothesized by Markowitz in 1952 - the very shape Kahneman and Tversky rejected when introducing Prospect Theory.

Although originally intended as merely a review, this paper makes an additional contribution in that it clarifies the concepts of adaptation and relativity as used in Prospect Theory. It is quite commonly believed that Prospect Theory presents a relative approach to decision making as it introduced the concept of gains and losses ${ }^{2}$. Even recently, there has been a good deal of discussion over the question of where the single reference point is located: either it is the current wealth value as proposed by Kahneman and Tversky (1979) or some other value depending on the considered outcomes or any recent windfalls. However using a single reference point is only half the relativity approach as two reference points might be assumed. The first is the minimum outcome and is typically close to the current wealth value. The second strongly depends on the attention focus but typically equals the maximum outcome of the

\footnotetext{
${ }^{2}$ This in itself is a misunderstanding as this concept was first noted by Markowitz (1952).
} 
prospect. These two points define the range of considered options. Relativity in this sense is mathematically defined in terms of the ratio rather than the difference.

This paper is also presenting a discussion with some other opinions on the different kinds of adaptation. For instance, Frederick and Loewenstein (1999) differentiate between "shifting adaptation level" and "desensitization", although this fails to capture the essence of range adaptation.

Finally, the paper (hopefully) presents a nice mosaic of opinions on the topic of adaptation from different academic disciplines. The literature on adaptation is vast. I was confronted with the problem of whether to present the subject by using my own words or by citing other authors who have already covered it in their many excellent books and articles. I opted for the second approach if for no other reason than to avoid the charge of misinterpreting and/or misrepresenting the concepts and opinions of others. This approach hopefully helps encapsulate the two kinds of adaptation and relativity.

The remainder of the paper is organized as follows. Point 2 is devoted to the different meanings of adaptation at the evolutionary, neural, sensory, environmental and mental levels. Point 3 shows how utility in economics makes use of the concept of adaptation. Point 4 describes Helson's Adaptation-Level Theory and Parducci's Range-Frequency Theory. Point 5 presents a more detailed analysis of the two kinds of adaptation. Point 6 considers the different kinds of relativity that result from different adaptation processes. Point 7 presents a discussion showing that the adaptation model adopted by Prospect Theory does not reflect the perception system, stymies the description of more complex behaviors, and results in an unnecessarily complicated model.

\section{Different Meanings of Adaptation}

\subsection{Evolutionary Adaptation}

Evolutionary adaptation was first described by British natural theologians John Ray (1627-1705) and William Paley (1743-1805). The theory was later refined by Charles Darwin (1809-82) in his "Origin of Species by Means of Natural Selection: Or, the Preservation of the Favoured Races in the Struggle for Life" (1859). Peter Medawar, winner of the Nobel Prize for Medicine and Physiology in 1960, describes the term as "a process allowing organisms to change to become better suited for survival and reproduction in their given habitat". Rappaport (1971) defines adaptation as "the processes by which organisms or groups of organisms maintain homeostasis in and among themselves in the face of both short-term envi- 
ronmental fluctuations and long-term changes in the composition and structure of their environments".

Adaptation is frequently understood as a property/feature or effect of change rather than the process itself. The Oxford Dictionary of Science defines adaptation as "any change in the structure or functioning of an organism that makes it better suited to its environment". Another definition states that "an adaptation is an anatomical, physiological, or behavioral trait that contributes to an individual's ability to survive and reproduce ('fitness') in competition with conspecifics in the environment in which it evolved" (Williams, 1966). Summarizing "adaptation can refer to a trait that confers some fitness on an animal, but it also represents the process by which that trait has come about" (Greenberg, 2010).

2.2. Neural (sensory) adaptation

"Neural or sensory adaptation is a change over time in the responsiveness of the sensory system to a constant stimulus. More generally, the term refers to a temporary change of the neural response to a stimulus as the result of preceding stimulation". This Wikipedia definition $^{3}$ is close to those met in academic texts: "Adaptation in the context of sensation refers to the fact that a prolonged and uniform sensory stimulus eventually ceases to give rise to a sensory message" (Medawar, 1983). "Adaptation can be simply defined as a change in the relationship between stimulus and response that has been induced by the level of stimulus", (Laughlin, 1989). "On the phenomenological level, (neural) adaptation is the change of the strength of the neuronal response during prolonged stimulation (typically decrease). This is commonly observed in experiments, in which a sensory or current stimulus is transiently turned on, usually preceded by a situation, in which the neuron is not excited. Then, the neurons start to respond strongly, and this response will decay and eventually reach a steady state value... However, this does not automatically imply that this change provides means for the sensory system to be adjusted to the current environment. The phenomenological perspective rather looks on the process of adaptation, while the functional view focuses on the result (i.e. on a change to become better suited to the current environment an individual animal is confronted with)" (Hildebrandt, 2010).

The best example of the neural adaptation is eye adaptation. "The human eye can function from very dark to very bright levels of light - its sensing capabilities reach across nine orders of magnitude. However, in any given moment of time, the eye can only sense a

\footnotetext{
${ }^{3}$ More and more Wikipedia citations are being encountered in research papers, although they are seldom acknowledged as such.
} 
contrast ratio of one thousand. What enables the wider reach is that the eye adapts its definition of what is black. The light level that is interpreted as 'black' can be shifted across six orders of magnitude - a factor of one million” (Wikipedia). Similar mechanisms are well attested for smell, temperature, taste, pain and touch (Gregory, Colman, 1995). "Someone who goes into a room containing a bowl of roses may smell them at first, but then become unaware of them. Once this process of sensory adaptation has occurred, no effort of attention can call smell to mind" (Medawar, 1983).

\subsection{Environmental Adaptation}

The definitions presented so far all assume that it is the living organism which adapts to changing environmental conditions. However, from the standpoint of a human being, adaptation may be seen as a process of changing the external world to suit its requirements. This was best expressed by Leakey (1981) as follows: "Animals adapt themselves to environment, hominids adapt environment to themselves using tools, language and complex cooperative social structures". This concept of adaptation is employed in contexts like film, theatre and literary adaptation, and is understood as both a process producing a particular result and the result itself. People tend to adapt more complex problems to suit their own intellectual capabilities, just as a scriptwriter has to squeeze the content of a multi-plot novel into a two-hour movie script. This is usually accomplished by transforming and simplifying complex ideas into something less complicated and more readily comprehensible.

The concept of adaptation can be used bilaterally to describe the same situation. For instance, a person could be said to adapt to variable light conditions, or alternatively, to adapt those variable light conditions to the optimal level at which the brain can process incoming information via the mechanisms of eye adaptation.

\subsection{Mental Adaptation}

Mutual human - environment interaction was described by the famous Swiss psychologist Jean Piaget, who "considers in fact intelligence rising from mental adaptation, where the adaptation is the equilibration of the action of an organism on the environment (assimilation) and of the action of the environment on the organism (accommodation). The subject assimilates the external world into existing structures (initially consisting in only inherited mechanisms) and updates them according to the experienced transformations, thus it accommodates them to the external objects" (Maniezzo, Roffilli, 2005).

In the author's opinion, the term "mental adaptation" is best expressed as "the state of not thinking about certain phenomena". This definition follows the Sulavik (1997) paper on 
mental adaptation to death in the case of professional rescuers, although it can easily be extended to cover many other situations like stress, major illness, bereavement, financial loss, immigration (Jasinskaja-Lahti, 2006), disasters (Leon, 2004) or even space travel (NASA). It has been proved that many difficulties with mental adaptation have a biological basis and are marked by MAO (monoamine oxidase) activity (Giraldi et al, 2007). The resulting depression and anxiety states are therefore treated by its inhibitors (MAOI). Returning to a healthy psychic state requires that those unpleasant, and sometimes tragic, experiences not be dwelled upon so intensely, if at all. It should be borne in mind that mental adaptation occurs in positive situations as well - financial windfalls, professional achievements, falling in love etc.

"Hedonic treadmill" is another term for mental adaptation coined by Brickman and Campbell (1971) "to describe the now widely accepted notion that though people continue to accrue experiences and objects that make them happy - or unhappy - their overall level of well-being tends to remain fairly static. The logic behind this argument stems from adaptation level theory (Helson, 1964), which argues that people perceive objects not in any absolute sense, but rather relative to a level established by previous experiences. Therefore, when people experience a positive event, two effects take in place: in the short run, well being increases; in the long run, however, people habituate to their new circumstances, which diminishes the positive effect of that event" (Mochon et al., 2008). "Perhaps the most dramatic evidence for this hypothesis was the finding that lottery winners were not particularly happy and that paraplegics were not much less unhappy than most readers would have anticipated" (Kahneman, 1999). This means that people adapt to their current situation and report a similar level of happiness.

\subsection{Evolutionary basis}

There are several other meanings of adaptation encountered in the literature (e.g. social adaptation). A wide coverage of hedonic adaptation examples is given by Frederick and Loewenstein (1999). Nevertheless, most of them have a common feature, viz. they signify a shift of either the organism's structure or its perception system to a new level. As a result, people (and animals) become better suited to external conditions, do not sense any more external stimuli, and cease to think about certain phenomena. This process or trait definitely has an evolutionary basis. As Medawar (1983) stated: "In a sense all evolution is adaptation". Failure to adapt would unnecessarily sap limited brain resources needed to perceive new stimuli and, in the extreme case, bring about the extinction of the species. Burying the past is therefore a prerequisite to experiencing the present and the future. 


\section{Adaptation in Utility Considerations}

As the concept of adaptation is so widely accepted, its appearance in utility considerations should come as no surprise.

3.1. In 1952, Harry Markowitz published an article entitled "The Utility of Wealth" in which he presented his utility function hypothesis (see Figure 3.1a). Although Markowitz does not employ the concept of adaptation, the shape of the curve he proposes suggests that such an assumption was implicit. Markowitz noted: "To summarize my hypothesis: the utility function has three inflection points. The middle inflection point is defined to be at the 'customary' level of wealth. Except in cases of recent windfall, customary wealth equals present wealth".
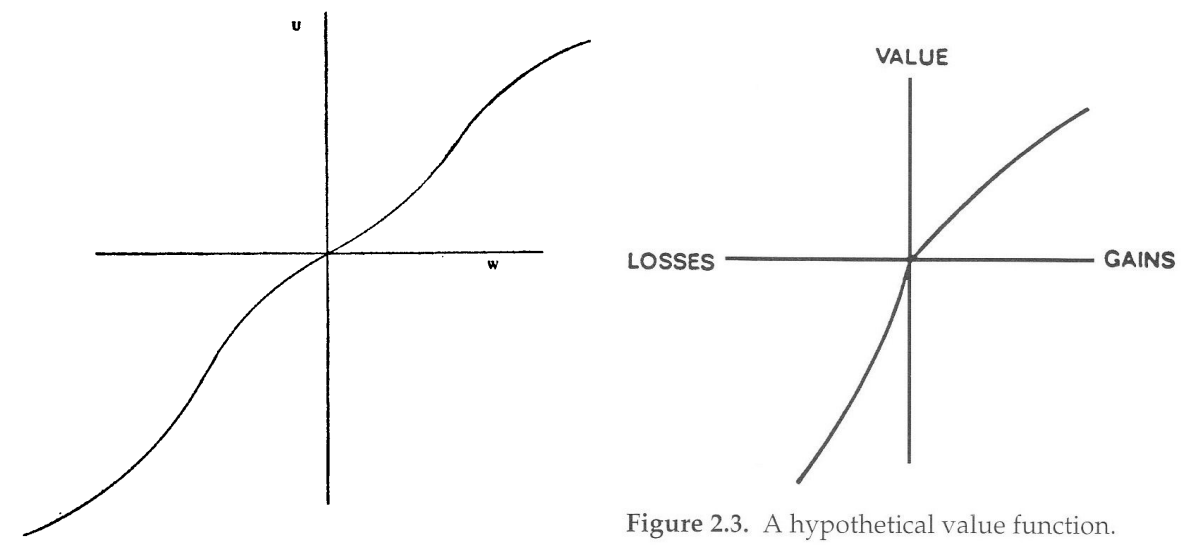

Figure 3.1. Left - Markowitz Utility Function (1952); Right - Prospect Theory Value Function (1979).

Markowitz states that the present value of wealth becomes the reference point for utility considerations, although he also stresses that the middle inflection point may not match this value due to recent experiences. In adaptation terms, this may be explained as an individual's failure to mentally adapt to his or her new net worth when this is suddenly changed.

3.2. A very similar approach, albeit with a differently shaped utility function (Figure 3.1b), was proposed by Kahneman and Tversky when publishing their Prospect Theory in 1979. Kahneman and Tversky explain: "An essential feature of the present theory is that the carriers of value are changes in wealth or welfare, rather than final states. This assumption is compatible with basic principles of perception and judgment. Our perceptual apparatus is attuned to the evaluation of changes or differences rather than to the evaluation of absolute magnitudes. When we respond to attributes such as brightness, loudness, or temperature, the past and present context of experience defines an adaptation level, or reference point, and stimuli are perceived in relation to this reference point (Helson, 1964). Thus, an object at a 
given temperature may be experienced as hot or cold to the touch depending on the temperature to which one has adapted. The same principle applies to non - sensory attributes such as health, prestige, and wealth" (Kahnemann, Tversky, 1979). As a result, Prospect Theory presented the value function as a function of gains and losses expressed in absolute terms.

The above quotation would suggest that Prospect Theory has a solid psychophysical basis. This, however, is not entirely true. As will be shown in the following points, Kahneman and Tversky (as well as Brickman and Campbell in their hedonic treadmill hypothesis) applied Helson's Adaptation-Level Theory whereas more modern theories may offer a better explanation of people's judgments.

\section{Helson vs. Parducci}

4.1. Helson (1964) argued that adaptation may represent a fundamental "law" of cognition and behavior. His Adaptation-Level Theory holds that the quality and magnitude of a response is a function of the distance above or below the adaptation level - a subjective point of equality at which stimuli are neutral. "AL theory maintains that this neutral or adapted background stimuli provide a basis, frame of reference, or standard against which new stimuli are perceived" (Roeckelein, 1998). "Helson defines Adaptation Level as a weighted logarithmic mean of all past and present stimulation on a given dimension. As each new stimulus is presented, it will be averaged into the computation of a new $A L$ ” (Eiser, 1986). The theory is described in more detail by Anderson (who, by the way, criticized it, 1992): "Helson stressed the importance of context effects in psychophysics and perception. The response to a focal stimulus could not be understood without reference to context and background stimuli. Helson claimed to have found a general solution with the concept of adaptation. The entire stimulus field was reduced to a single value, the adaptation level (AL), and the focal stimulus was judged relative to this $A L$. The adaptation level (AL) was taken to be a pooled average of all relevant stimuli" (including past ones). Anderson then goes on to say: "The AL is only one step towards perceptual value. The perceptual value of any stimulus is determined by a ratio comparison to the $A L$ ". As Helson attempted to use Fechner's logarithmic formula, the perceptual value is the difference between the logarithm of stimulus $S$ and the logarithm of $A L$. Adaptation-Level Theory therefore considers $A L$ as the neutral point, or "zero of function". "The essence of Helson's version is that the stimulus that is experienced as 'neutral' or 'average' (the adaptation level), is simply the average stimulus; other stimuli are judged higher or lower in proportion to their differences from this average” (Birnbaum, Parducci, 1995). 
This is the concept which, with some modifications, is implemented in Prospect Theory ${ }^{4}$.

4.2. "Despite of AL theory's strong influence on psychophysical and perceptual theorizing during the fifties and sixties (Appley, 1971), subsequent investigations of the AL model have demonstrated major theoretical and empirical limitations" (Geissler, 1983). This was presented in several studies by Parducci (1963, 1965), Sarris (1967, 1971), Johnson (1972), and Anderson (1974). Birnbaum (1974), among others, has shown that the mean ratings of two sets of numerals are inconsistent with Adaptation-Level Theory because they shift more rapidly where numerals are spaced more closely. "Helson did not recognize that a higher order cognitive operation takes place in the construction of standards used in the evaluation process, that contextual information is actively - though not necessarily consciously - selected. Today, the accepted theory of comparative judgment is the Range-Frequency Compromise theory put forward by Parducci (1961)" (Nussbaum, 2004). "Parducci and coworkers sought to go beyond Helson's simple idea that people respond to the mean or average of their sensory experiences in determining the frame of reference for judgment. Instead they asserted that the entire distribution of items in a psychophysical experiment would influence the judgments of a particular stimulus" (Lawless \& Heymann, 1998).

Parducci in his Range-Frequency Theory describes psychophysical judgment as a compromise between two principles: the range principle, and the frequency principle. "The range principle assumes that differences in response are directly proportional to differences in subjective value and inversely proportional to the range of subjective values. Subjects tend to locate each stimulus relative to the subjective end values" (Birnbaum, 1974). Parducci (1983) explains that: "The place of a stimulus in the range is reflected in the following definition:

$R_{i}=\left(s_{i}-s_{\min }\right) /\left(s_{\max }-s_{\min }\right)$

where $R_{i}$ is the range value, with $s_{\min }$ and $s_{\max }$ representing the lowest and highest of the stimulus values in the context of stimuli affecting the judgment of $s_{i} . R_{i}$ is thus a proportion that can take any value between 0 and 1 ".

On the other hand "the frequency principle asserts that differences in response tend to

\footnotetext{
${ }^{4}$ It has to be added that there are some differences. First, Prospect Theory takes current wealth as its reference point whereas Adaptation-Level Theory takes the average value of all stimuli. For example, in the case of a prospect having two outcomes $\$ 0$ and $\$ 100$, the reference point assumed by Prospect Theory is $\$ 0$, whereas AL Theory assumes a value of $\$ 50$. Second, AL Theory assumes the perceptual value to be the difference between the logarithms of the stimulus and the AL, whereas Prospect Theory assumes it to be a power function of the difference between the stimulus and the reference level. It is not the purpose of this paper to analyze how these changes affect the perception value by making a comparison with Helson's approach. The main thing to note is that Prospect Theory adopts the concept of a single level and this becomes the reference for further considerations.
} 
be proportional to differences in stimulus rank" (Birnbaum, 1974) and the final judgment function is a weighted sum of both principles.

Most of the Parducci's work, as well as that of other researchers, was devoted to analyzing the stimulus distribution and noting that its skewness impacts people's judgments. "For example, Birnbaum (1992) demonstrated that the selection of certainty equivalent was influenced when skewing the distribution of options offered as certainty equivalents for simple prospects, while holding the maximum and minimum constant" (Vlaev, Chater, 2006). Parducci himself considered this their major achievement. "Some of my early data were consistent with adaptation-level theory: adaptation level tended to be close to the mean of the stimuli, just as the theory asserted. However, the ratings for skewed or asymmetrical sets of stimuli were not balanced at 'neutral' or 'average", (Parducci, 1995).

4.3. From the viewpoint of the present review, there is, however, another result of much greater importance, viz. that Range-Frequency Theory considers ranges of stimuli and assumes relativity within these ranges. This differs from Helson's approach, which considers stimuli relatively, but only to a certain level. To put it in another way: Helson's theory assumes one reference point (adaptation level), whereas Parducci's theory assumes two reference points (minimum and maximum stimulus). As a result, Adaptation-Level Theory assumes that all stimuli changes are expressed in absolute terms, whereas Range-Frequency Theory asserts that those changes are expressed in relation to the stimuli range.

This difference between theories is rarely discussed in the literature as it does not influence category judgments. It does, however, have important consequences for determining perception levels. As the stimulus range can be, at least theoretically, unlimited, so can the perception range according to Helson's theory. This is certainly not an intuitive assumption regarding the human perception system. Further, the perception of a given stimulus (say 101) in the context of a given adaptation level (say 100) is constant whatever the range of other stimuli. This would assume a constant sensitivity to a given stimulus change. However, the difference between 101 and 100 may be considered to be substantial in the stimuli range of 95-105, but small in the stimuli range of $0-200$. This observation is naturally embedded in Range-Frequency Theory, although apparently not overly emphasized, even by its author.

The reasoning presented in this sub-point shows that Helson's approach is incorrect from the perception viewpoint as the perception range is limited and sensitivity varies with stimulus range. This topic will be discussed in more detail in the next point. 


\section{Kinds of Adaptation}

5.1. Although Adaptation-Level and Range-Frequency are the underlying theories, more recent studies provide a deeper explanation of adaptation at the sensory level. Although there is a rich literature on this subject, we will confine ourselves here to the "Adaptation and the Phenomenology of Perception" review by Webster, Werner, and Field, which mostly covers visual cognition. The authors state: "The use of information theory has provided major insights into understanding of sensory coding. Neurons have a limited dynamic range, and because they are noisy can reliably signal only a relatively small number of response levels (Barlow and Levick, 1976). To maximize the information a neuron can carry, these levels should be matched to the distribution of levels in the stimulus. This principle closely predicts evolutionary adaptations such as the sigmoidal shape of a neuron's response function (Laughlin, 1987)”.
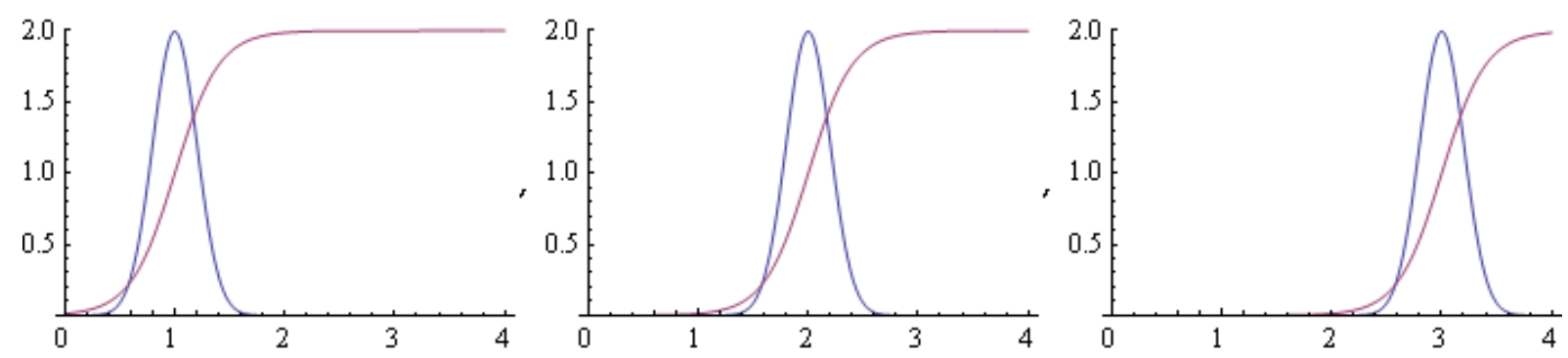

Figure 5.1. Distribution of the stimuli and the sigmoidal shape of a neuron's response function for three different average stimulus values. The drawings are based on the paper by Webster et al.

The authors explain this observation in more detail (see Figure 5.1): "Most points in a scene have a brightness and color that are close to the modal level, and thus the optimal response function should be steep near the mode, to allow fine discrimination among frequently occurring stimulus values, while shallow at the tails, where signals are rare. This effectively expands the representation of data near the modal level and compresses those data near the outliers. By adjusting to the average stimulus the visual system could represent information by the deviations from the average. This gives special importance to the mean because it defines the reference point to which other responses are now relative”.

5.2. The process of shifting the reference point, which we call here level adaptation, should, however, be carefully separated from another effect, known as range adaptation ${ }^{5}$, which is associated with increasing or decreasing receptor sensitivity. As Webster continues: "In addition to the average stimulus, to realize its full capacity a neuron's operating curve should also be matched to the range of stimulus levels, or available contrasts. This form of

\footnotetext{
${ }^{5}$ The term "distribution adaptation" would even be better, but it would overcomplicate further considerations on the number of reference points and the notion of relativity.
} 
adjustment, known as contrast adaptation, is also well established both in individual neurons and psychophysically" (Webster, 2003). Thus, for example, sensitivity to contrast is reduced in the presence of high contrast stimuli".
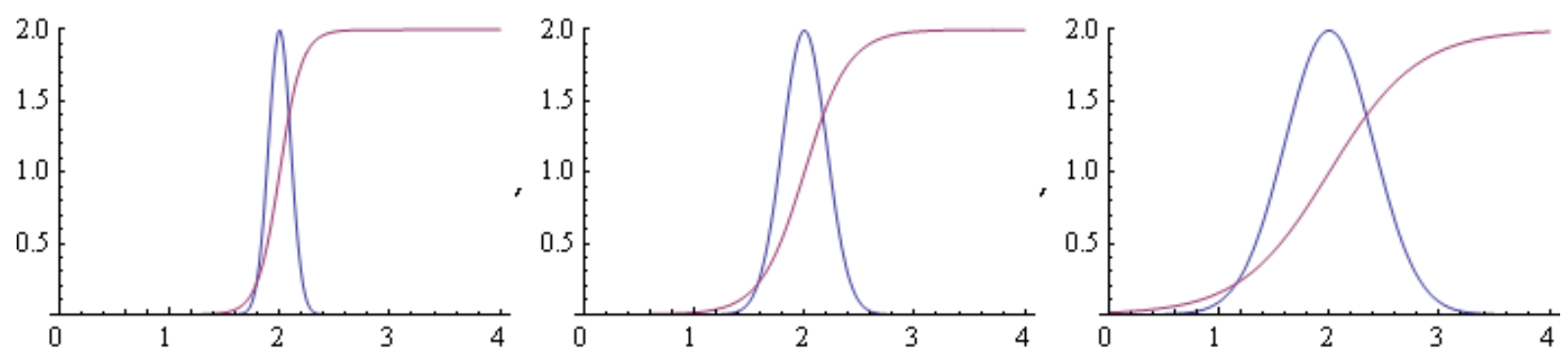

Figure 5.2. Distribution of the stimuli and the sigmoidal shape of a neuron's response function for three different stimulus deviations. The drawings are based on the paper by Webster et al.

The range effect can be described as succinctly as it was by Lawless and Heymann (1998): "Short ranges produce steep psychophysical functions, and wide ranges produce flatter functions". Very clearly, this varying sensitivity may be mathematically expressed as the derivative of the psychophysical function. The narrower the range, the greater the sensitivity; the wider the range, the lower the sensitivity.

An interesting example of range adaptation is given by Parducci (1995): "On tropical islands where the temperature is almost always in the 80s, the natives are sensitive to differences that seem hardly noticeable to us; thus, they complain of the extremes, of the heat when the temperature is in the high 80s, of the cold when it is in the low 80s". However, a varying sensitivity may affect not only the sensory, but also the mental system. For example, focusing attention on part of a problem increases sensitivity to its details. Focus broadening, by contrast, decreases this sensitivity. Changing sensitivity in response to changing stimulus values may also be observed with monetary outcomes. For instance, an absolute amount of money (say \$10) may be relevant for a person shopping for goods worth $\$ 100$ but completely irrelevant to the same person purchasing a house for $\$ 500,000$. This means that sensitivity to financial stimuli is dependent on range as in the neuronal context.

A nice range adaptation analogy is given by Robson in his deliberations on biology, evolution and human nature. Robson (2002) states: "Possessing utility that has a relative and local scale, rather than an absolute or global scale, may be biologically advantageous... This issue may be analogous to the use of a voltmeter. To obtain an accurate reading from this device, it is necessary to first estimate the range in which the unknown voltage fails. Only if the right range is selected on the device, such that the needle moves to the middle of the scale, is an accurate reading obtained". In another paper, Robson (2001) analyzes an example of 
choosing between two alternatives represented as numbers drawn from the same continuous cumulative distribution function. Robson concludes that "it is optimal for utility to adapt to the distribution $F$ ". By this, he means adapting to the range and frequency of options as proposed by Parducci.

5.3. The evidence presented so far shows that two kinds of adaptation are present: level adaptation and range adaptation. In the visual system, different mechanisms are responsible for brightness (level) and contrast (range) adaptation. There is an evidence that these two mechanisms work in tandem (Mante et. al, 2005, Wark et. al, 2007) ${ }^{6}$.

The distinction between these two kinds of adaptation, however, is not so precisely noted in the psychology literature. For instance Frederick and Loewenstein state in their "Hedonic Adaptation" paper (1999): “Although we have used the term 'adaptation' broadly to denote anything that reduces the subjective intensity of a given stimulus, it is important to distinguish between adaptive processes that diminish subjective intensity by altering the stimulus level that is experienced as neutral (shifting adaptation levels) and adaptive processes that diminish the subjective intensity of the stimulus generally (desensitization)". This sentence might suggest that they distinguish the same, two kinds of adaptation.

As it turns out, however, "desensitization" has little to do with range adaptation. It is understood as yet another process of decreasing stimuli amplification in the case of "hardened", "jaded", or "jaundiced" people, who "are typically unmotivated to make any kind of change, whether local or global". The opposite of "desensitization" is "sensitization", which means that "hedonic intensity of a constant stimulus increases over time". An example of this is "the increasing irritation produced by exposure to a disliked roommate" (Frederick, Lowenstein, 1999).

Hedonic adaptation is therefore mainly understood as "shifting adaptation levels". On the other hand, the authors state that "shifting adaptation levels preserve or enhance sensitivity to stimulus differences", and that "hedonic adaptation may also increase our sensitivity to, and motivation to make, local changes in our objective circumstances". Obviously, "increasing sensitivity" here means something other than "sensitization". To illustrate this effect, the authors consider a man who has been incarcerated. The authors do not recognize his increas-

\footnotetext{
${ }^{6}$ It is not the purpose of this paper to discuss the details of this topic. Once it is known, however, how adaptation systems work, their dynamic behavior can be easily predicted. In a steady situation, stimuli (like temperature or odors) are not perceived (thanks to level adaptation), and the perception system is tuned to be highly sensitive to stimuli changes (thanks to the adaptation to their narrow range). In the case of a sudden stimuli change, sensitivity decreases (as the stimulus range widens), and the perception system starts to adapt to the new stimulus level and sensitivity increases once more. Evolution has done a perfect job: this is how some modern automatic gain control amplifiers work.
} 
ing sensitivity to the jail size as the result of a separate adaptation process. They try to explain both his shifting to a new adaptation level (being incarcerated) and his increasing sensitivity (to the jail size) by using the value function of Prospect Theory. The presented explanation, however, is only seemingly correct ${ }^{7}$.

5.4. Admittedly, Frederick and Loewenstein also consider the subject of multiple reference points and come to conclusions which are very similar to those presented in this paper: "The literature on sensory and perceptual adaptation has commonly assumed that the adaptation level in a particular domain can be characterized by a single summary number... However, the effect of past stimuli cannot be summarized so simply" (as a single adaptation level). They consider "an individual who earned \$20,000 annually for her first six years on the job, got a promotion that raised her salary to $\$ 50,000$, then was transferred two years later to a different department where she earned \$40,000". The authors pose the question: "What is her adaptation level income?" and answer that: "It is possible that she compares her current salary to a single adaptation level lying somewhere between \$20,000 and \$50,000. It seems more likely, however, that she has two different adaptation levels - one at \$20,000 and the other at \$50,000 - that are invoked in different situations and both of which contribute to her satisfaction or dissatisfaction with her current salary". They conclude by stating that "although the issue of multiple reference points has been raised, their formation and relative weighting has not been investigated empirically".

It seems that the alternative presented by Frederick and Loewenstein has still not been tested - even in more recent studies. Most of the papers that deal with multiple reference points are concerned with the effect of shifting a single adaptation level (see for instance Schwartz et al., 2008). The Prospect Theory paradigm is so strong that it is nigh impossible to find any attempt to analyze the concept of two reference points defining the range of considered values.

5.5. It has to be added that choosing the range with the minimum and maximum values of the options under consideration may only be a simplified model of the cognition process. This is due to the state of attention. According to a classical definition: "Attention is the tak-

\footnotetext{
${ }^{7}$ The explanation is made graphically using a very curved value function an a low loss aversion factor. Although most probably intended as an illustration only, the solution should also be mathematically correct. The inequality on page 304 can be presented more generally as $(r-1)^{\alpha}>\lambda r^{\alpha}-\lambda$, where $r$ is the ratio of two options $(r>1)$. It is easy to check that, using the Prospect Theory parameterization, this inequality only holds for $r$ in the range $[1.0,1.003]$, which is clearly too narrow to claim that the phenomenon of increasing sensitivity has been explained using the value function. This merely shows that it is extremely difficult to explain a given phenomenon using a theory which is not aware of it.
} 
ing possession by the mind of one out of what seem several simultaneously possible objects or trains of thought" (James, 1890). Keegan (2010) differentiates Focused and Divided attention: "Focused attention is the kind of attention we use when we are actively attending to something. It is our ability to attend to one thing to the exclusion of everything else". Robbins (2000) differentiates Sustained, Divided and Selective (Focused) attention and claims that the last is deployed "where an animal has to focus resources on a restricted number of sensory channels while ignoring the rest". From the above definitions, it follows that focused attention is the state of highest concentration of attention which (according to James' classical definition), "implies withdrawal from some things in order to deal effectively with others".

These definitions indicate that people concentrate on the range of options considered in the state of focused attention. This is especially the case under experimental conditions as those surveyed are remunerated for their participation and are paid to focus their whole attention on the problems being analyzed. However, since attention and its degree of concentration decide the choice of reference values and, since there are other signals and issues vying for attention, it may be assumed that other quantities are potential reference values. This may explain why the decision or judgment process is often influenced by random events (anchoring). A more detailed discussion of this topic, however, is beyond the scope of this paper.

\section{Kinds of Relativity}

6.1. It should be clear from the considerations presented so far, that both kinds of adaptation lead to different notions of relativity. Level relativity means that stimulus changes are represented in absolute terms. This concept is employed by Prospect Theory, which assumes that gains and losses are perceived in terms of monetary amounts. This is best exemplified by the form of the value function:

$$
v(x)=\lambda|x|^{\alpha}
$$

where $x$ (a gain or a loss) is expressed in absolute terms.

Range relativity assumes that stimulus changes are perceived in relative terms as a proportion of the stimulus range (see point 4.2). This approach is not implemented by Prospect Theory, as it would require that the value function be defined as a function of relatively expressed outcomes.

The lack of a clear distinction between the two kinds of relativity leads to the generally held view that Prospect Theory adopts a relative approach to decision making. This, however, is only half true. 
6.2. Citations concerning (level) relativity need not be presented here as they are encountered in almost every text on the subject. However, the question as to whether range relativity is admitted by modern behavioral economics is a legitimate one and, in contrast to range adaptation, is answered with an unqualified "yes".

First, Mental Accounting as proposed by Thaler $(1980,1999)$ is "the set of cognitive operations used by individuals and households to organize, evaluate, and keep track of financial activities". As Thaler explains: "Expenditures are grouped into categories (housing, food, etc.) and spending is sometimes constrained by implicit or explicit budget...Money in one mental account is not a perfect substitute for money in another account". As each account differs in size, the effect described may be attributed to range relativity.

Thaler (1999) also reconsiders the well known example, first discussed by Savage (1954), that "most people say that they will travel to save the $\$ 5$ when the item costs $\$ 15$ but not when it costs $\$ 125$ ". Thaler explains that: “five dollars seems like a significant saving on a $\$ 15$ purchase, but not on a $\$ 125$ purchase”. Thaler (1980) proposes that "search for any purchase will continue until the expected amount saved as a proportion of the total price equals some critical value. This hypothesis is a simple application of the Weber-Fechner law of psychophysics. The law states that the just noticeable difference in any stimulus is proportional to the stimulus" (emphasis added). Thaler obviously talks about the range relativity effect, however he then engages Prospect Theory to explain this phenomena.

The concept of mental accounts is also considered by Kahneman and Tversky (1985), who define minimal, topical, and comprehensive accounts. "The minimal account includes only the difference between the two options. A topical account relates the consequences of possible choices to a reference level that is determined by the context within which the decision arises. A comprehensive account incorporates all other factors including current wealth, future earnings, possible outcomes of other probabilistic holdings" (Kahneman, Tversky 1984, Thaler, 1999). Kahneman and Tversky conclude: "We suggest, however, that people spontaneously frame decisions in terms of topical account" and that "The topical organization of mental accounts leads people to evaluate gains and losses in relative rather than in absolute terms" (emphasis added). This conclusion is obviously in full accordance with the concept of range relativity.

Interestingly, the concept of range relativity has reappeared in more recent papers. For instance: "Stewart et al. (2003) argued for the existence of what they called prospect relativity: that the perceived value of a risky prospect is relative to other prospects with which it is 
presented. The prediction is that the option set will affect people's choices because there is no fixed internal scale according to which people make their judgments of the values of certain options. People's expressed (or revealed) risk preferences are not absolute, but are, to some degree at least, relative to the range of available options" (Vlaev and Chater, 2007).

An interesting confirmation of range relativity was recently reported by Baltussen, Post and Van den Assem (2007). The authors used an extensive sample of choices from ten different editions of the high stakes TV game show "Deal or No Deal". "In each sample, contestants respond in a similar way to the stakes relative to their initial level, even though the initial level differs widely across the various editions. Amounts therefore appear to be primarily evaluated relative to a subjective frame of reference rather than in terms of their absolute monetary value" (Baltussen, Post, Van den Assem, 2008). To summarize, the absolute amount of a given deal is not crucial; what matters most is its ratio to the initial stake.

As presented, range relativity is an effect well known to Kahneman and Tversky, and other researchers. It is, however, important to note that Kahneman and Tversky published on this subject in the 1980s, whereas Prospect Theory was introduced in 1979 and its underlying assumption is level relativity, i.e. that gains and losses are perceived as monetary amounts. This assumption remained unchanged in the cumulative version of this theory introduced in 1992.

\section{Discussion}

It may be argued that the way in which gains and losses are represented (i.e. in absolute or relative terms) does not matter as Prospect Theory can explain the range effects by comparing the prospect values of two options. It may be also argued that this kind of representation does not influence choices between the two options for the same reason. This is true but this line of reasoning is only partially satisfactory.

This is because the assumption of one reference (adaptation) level, together with the assumption that gains and losses are perceived in absolute terms, does not reflect the human perceptual system. This may be summarized as follows: according to Prospect Theory, a prospect value may even assume an infinite value; a given monetary amount (like \$10) has a constant psychological value; and the sensitivity to a given amount is constant whatever other amounts under consideration. This means that the underlying principle of Prospect Theory is psychophysically incorrect.

Another argument against the Prospect Theory approach is that level adaptation and the resulting single reference point is too simplified a model to describe the complexity of 
human behavior. This has been shown by Parducci in his Range-Frequency Theory, and stated by many other researchers since then (including Frederick and Loewenstein). This assumption therefore prevents the theory from being able to describe and explain more complex behavioral patterns.

Finally, the kind of adaptation adopted as the basic principle has a surprising impact on the shape of the decision making model. Kontek (2009) has shown that the assumption of absolute notion of gains and losses, inevitably leads to the design of a theory that incorporates the concept of probability weighting. On the other hand gains and losses expressed in relative terms, lead to a model that does not require probability weighting in order to describe lottery experiments. This means that level adaptation leads to a more complex decision making model.

The review and considerations presented in this paper may, therefore, be of significance to future decision-making theories.

\section{References:}

Anderson, N. H., (1992). Integration Psychophysics and Cognition. In Psychophysical Approaches to Cognition, Algom D. (Editor), Advances in Psychology, Elsevier Science Publishers, 92.

Baltussen, G., Post, T., Van den Assem, M. J., (2008) Risky Choice and the Relative Size of Stakes. SSRN Working Paper http://ssrn.com/abstract $=989242$.

Birnbaum, M. (1974). Using contextual effects to derive psychophysical scales. Perception \& Psychophysics, 15, pp. 89-96.

Birnbaum, M. (1992). Violations of monotonicity and contextual effects in choice-based certainty equivalents. Psychological Science, 3 (5), pp. 310-314.

Brickman, P., Campell, D. (1971). Hedonic relativism and planning the good society. In M. H. Appley (Editor.), Adaptation-level theory: A symposium (pp. 287-302). New York Academic Press.

Darwin, C. (1859). "Origin of Species by Means of Natural Selection: Or, the Preservation of the Favoured Races in the Struggle for Life".

Eiser, J. R., (1986). Social Psychology. Cambridge University Press.

Frederick, S., Loewenstein, G. (1999). Hedonic Adaptation. In Kahneman, D., Diener, E. Schwarz, N. (Editors) Well-Being. The Foundations of Hedonic Psychology. Russell Sage Foundation. pp. 302-329.

Giraldi, T., De Vanna, M., Malagoli, M., Tuveri, G., Sutto, K., Schilliani, G., Grassi, L., (2007). Mental adaptation to cancer: depression and blood platelet monoamine oxidase activity in breast cancer patients. Anticancer Res., 27(3B), pp. 1715-9.

Greenberg, N., Adaptation defined. https://notes.utk.edu/bio/greenberg.nsf .

Gregory, R. L., Colman, A. M. (1995). Sensation and Perception. Longman Group Limited.

Hildebrandt, K., J., (2010). Neural adaptation in the auditory pathway of crickets and grasshoppers. Dissertation, Mathematisch-Naturwissenschaftlich Fakultaet, Humboldt-Universitaet, Berlin.

Jasinskaja-Lahti, I., (2008). Long-term immigrant adaptation: Eight-year follow-up study among immigrants from Russia and Estonia living in Finland. International Journal of Psychology, 43 (1), pp. 618. 
Helson, H., (1964). Adaptation-level theory. Harper \& Row, New York.

James, W. (1890). The Principles of Psychology. An Internet resource developed by Green, C. D. http://psychclassics.yorku.ca/James/Principles/index.htm

Kahneman, D., (1999). Objective Happiness. In Kahneman, D., Diener, E., Schwartz, N. (Editors), Well-Being. The Foundations of Hedonic Psychology. Russell Sage Foundation. pp. 3-25.

Kahneman, D., Tversky, A., (1979). Prospect Theory: An analysis of decision under risk. Econometrica, 47, pp. 263-91.

Kahneman, D., Tversky, A., (1984). Choices, Values, and Frames. American Psychologist, 39 (4), pp. 341-350.

Keegan, D. (2010). Psychology Site. http://www.gerardkeegan.co.uk/glossary/gloss_f.htm

Kontek, K., (2009). Absolute vs. Relative Notion of Wealth Changes. MPRA Paper http://mpra.ub.unimuenchen.de/17336/, Available at SSRN: http://ssrn.com/abstract=1474229 .

Laughlin, S. B., (1989). The role of sensory adaptation in the retina. Journal of Experimental Biology, 146, pp. 39-62.

Lawless, H. T., Heymann, H. (1998). Sensory evaluation of food. Chapman \& Hall., New York.

Leakey, R. E. (1981). Making of Mankind. E P Dutton.

Leon, G., R., (2004). Overview of the psychosocial impact of disasters. Prehosp Disast Med, 19(1), pp. 4-9.

Mante, V., Frazor, R. A., Bonin, V., Geisler, W. S., Carandini, M. (2005). Independence of luminance and contrast in natural scenes and in the early visual system. Nature neuroscience, 8(12), pp. 16901697.

Markowitz H., (1952). The Utility of Wealth. Journal of Political Economy, Vol. 60, pp. 151-158.

Maniezzo, V., Roffilli, M. (2007). A Psychogenetic Algorithm for Behavioral Sequence Learning. International Journal on Artificial Intelligence Tools, 16, pp. 195-217.

Medawar, P. B., Medawar, J.S., (1983). Aristotle to Zoos. A Philosophical Dictionary of Biology. Harvard University Press, Cambridge, Massachusetts.

Mochon, D., Norton, M. I., Ariely, D., (2008). Getting off the hedonic treadmill, one step at a time: The impact of regular religious practice and exercise on well being. Journal of Economic Psychology, 29, pp. 632-642.

Nussbaum, J. I., (2004). Inclusion and Exclusion: Implications for Stereotypic Judgments of Groups and Individuals. Senior Thesis in Social Psychology, Haverford College.

Parducci, A. (1965). Category judgment: a range-frequency model. Psychol. Rev. 72(6), pp. 407-18.

Parducci, A. (1983). Category Ratings and the Relational Character of Judgment. In Geissler, H.-G., Buffart, H.F.J.M., Leeuwenberg, E.L.J., Sarris, V. (Editors). Modern Issues in Perception. Advances in Psychology, 11, pp. 262-282. Elsevier Science Publishers., Amsterdam.

Parducci, A., (1995). Happiness, Pleasure, and Judgment. The Contextual Theory and Its Applications. Lawrence Erlbaum Associates, Inc. Mahwah, New Jersey.

Rappaport, R.A. (1971). Ritual, sanctity, and cybernetics. American Anthropologist, 73(1), pp. 59-76.

Robbins, T. W. (2000). Arousal and Attention: Psychopharmacological and Neuropsychological Studies in Experimental Animals. In Parasuraman, R. (Editor), The Attentive Brain. Massachusetts Institute of Technology.

Robson, A. J. (2001). The Biological Basis of Economic Behavior. Journal of Economic Literature, Vol. XXXIX, pp. 11-33. 
Robson, A. J. (2002). Evolution and Human Nature. The Journal of Economic Perspectives, 16 (2), pp. 89-106.

Roeckelein, J. E., (1998). Dictionary of theories, laws, and concepts in psychology. Greenwood Press.

Schwartz, A., Goldberg, J., Hazen, G. (2008). Prospect theory, reference points, and health decisions. Judgment and Decision Making, 3(2), pp. 174-180.

Sulavik, J., (1997). An elementary form of mental adaptation to death. Human Affairs, 2, December 1997.

Thaler, R. (1980). Toward a positive theory of consumer choice. Journal of Economic Behavior and Organization, 1, pp. 39-60.

Thaler, R. (1999). Mental Accounting Matters. Journal of Behavioral Decision Making, 12, pp. 183206.

Vlaev, I., Chater, N., (2007). Relativistic financial decisions: Context effects on retirement saving and investment risk preferences. Judgment and Decision Making, 2, pp. 292-311.

Wark, B., Lundstrom, B. N., Fairhall, A. (2007). Sensory adaptation. Current opinion in Neurobiology, 17, pp. 423-429.

Webster, M. A., Werner, J. S., Field, D. J. (2005). Adaptation and the Phenomenology of Perception. In Clifford, C., Rhodes, G. (Editors) Fitting the Mind to the World: Adaptation and Aftereffects in High Level Vision: Advances in Visual Cognition Series, Vol. 2, pp. 241-281. Oxford University Press.

Williams, G. C., (1966). Adaptation and natural selection; a critique of some current evolutionary thought. Princeton. 